This is a peer-reviewed, accepted author manuscript of the following research article: Banegas, D. L. (2013). ELT through videoconferencing in primary schools in Uruguay: first steps. Innovation in Language Learning and Teaching, 7(2), 179188. https://doi.org/10.1080/17501229.2013.794803

'Innovative Practice' article

\title{
ELT through videoconferencing in primary schools in Uruguay: first steps
}

Plan Ceibal is an interinstitutional undertaking which has distributed XO laptops and Internet connectivity among primary school learners and teachers across Uruguay and developed a wide range of educational programmes. Ceibal administration believes that it is imperative to introduce English as a Foreign Language (EFL) in primary education through the use of new modes of teaching which incorporate the OLPC XO laptop as a tool for learning engagement and democratisation. While the country lacks qualified teachers, it has the funds to support a project based on blended learning which integrates remote teaching through videoconferencing, the use of a learning management system (LMS), and professional development. Plan Ceibal seeks to demonstrate that lessons delivered by remote teachers (RT) via videoconferencing with support from classroom teachers (CT) with very limited or no command of English can facilitate successful learning outcomes in learners and classroom teachers. In this article, I describe the pilot phase of this project which aims delivering 5,000 remote lessons by 2015 .

Keywords: blended learning; Plan Ceibal; videoconferencing; remote teaching; XO laptop, EYL.

\section{Introduction}

Current innovations in foreign language classrooms may be linked to the presence of digital technologies as mediating tools in the social construction of knowledge. Within the technology domain, it is well-known that the One-Laptop-Per-Child organisation promotes the reduction of the digital divide by allowing children in developing countries to become computer literate through the use of an XO laptop (Randerson 2008). Considering education a political concern the government of Uruguay adopted the OLPC spirit and XO laptops through the implementation of the Plan Ceibal project with the aim of 'offering equal opportunities, the democratisation of knowledge, and the promotion of new forms of literary,' (Cyranek 2011, 32).

Plan Ceibal is an interinstitutional undertaking which has distributed XO laptops and Internet connectivity among primary school learners and teachers across Uruguay and developed a wide range of educational programmes which place Information and Communication Technologies (ICT) at the heart of pedagogical innovation. The implementation of such a project has given rise to the current investigation of aspects such as computer supported collaborative learning and autonomy (Mitra and Quiroga 2012).

Inscribed in this nation-wide scheme, a project called 'Plan Ceibal en Inglés' was born in 2012 and it was envisaged that it would bring together inputs from Plan Ceibal, Ministry of Education of Uruguay, and British Council. Ceibal administration believes that it is imperative to introduce English as a Foreign Language (EFL) in primary education through 
the use of new modes of teaching which incorporate the XO laptop, called Ceibalita as a tool for learning engagement and democratisation. While the country lacks qualified teachers, it has the funds to support a project based on blended learning which integrates remote teaching through videoconferencing, the use of a learning management system (LMS), and professional development. Plan Ceibal seeks to demonstrate that lessons delivered by remote teachers (RT) via videoconferencing with support from classroom teachers (CT) with very limited or no command of English can facilitate successful learning outcomes in learners, including effective interaction with the RT, CT, and between learners.

In 2012, a pilot phase was implemented in 20 primary schools thus reaching almost 1,000 Year 4 learners aged 10-11. It involved 40 CTs who volunteered to be part of the pilot phase, 20 RTs, three e-moderators, and a managing team of experts from Plan Ceibal and British Council. The project aims at delivering 5,000 remote lessons a week by 2015 .

Based on my experience as part of the team through the pilot phase and design of the expansion phase, I will describe the main features, impact, and implications behind Plan Ceibal en Inglés as an example of innovative practice in English Language Teaching.

\section{Project design}

Plan Ceibal en Inglés partnered with the British Council and through the latter two Argentinian experts (Banfi and Rettaroli 2012) developed a three-level course to cover Years 4, 5, and 6 of primary education combining telepresence and face-to-face teaching. Remote teachers and e-moderators were also based in Argentina and Colombia for the pilot phase.

Defined as 'a language course which combines a face-to-face classroom component with an appropriate use of technology' (Sharma and Barrett 2007, 7), blended learning is the teaching model underpinning Plan Ceibal en Inglés. According to Nissen and Tea (2012), blended learning solutions are more frequent given the benefits of combining media, contexts, modes of web-based technology, and traditional learning. In this model where ICT resources become powerful mediating tools, sociocultural and cognitive perspectives of learning underlie the whole experience (Helms 2012). Within this theoretical view, ICT use in ELT, or in learning in general, could be envisaged as a continuum which moves from ICT for teaching where only teachers use technology for managing and organising the classrooms to ICT for learning where learners are encouraged to develop their own resources (Erben, Ban, and Castañeda 2009). The movement from a teacher-centred practice to a learner-centred one entails the need to create tasks that consider learners' potential, computer literacy level, and the offering of new cognitive challenges (Starkey 2011). In turn, this shift in centredness towards negotiated practices promotes learner 
This is a peer-reviewed, accepted author manuscript of the following research article: Banegas, D. L. (2013). ELT through videoconferencing in primary schools in Uruguay: first steps. Innovation in Language Learning and Teaching, 7(2), 179188. https://doi.org/10.1080/17501229.2013.794803

autonomy, motivation, and web-mediated self-regulated learning (Ushioda 2011a, 2011b; Shen, Lee, and Tsai 2011).

I will now turn to describe how blended learning was implemented during the pilot phase between June and November 2012.

Each week, learners had three one-hour lessons called Lessons A-C. While Lesson A was taught remotely through videoconferencing by the qualified RT, Lessons B and C were led by learners' CT, who had little or no knowledge of English. Naturally, this entailed collaborative work between remote teachers and classroom teachers which was channeled through a weekly one-hour session through Skype. Following Banfi and Rettaroli (2012) this complex picture could be represented as follows (Figure 1):

\section{INSERT FIGURE 1 HERE}

Figure 1: Lesson cycle

\section{Lesson planning and materials development}

All materials and lesson plans were tailor made and discussed with Uruguayan stakeholders to produce cultural-responsive pedagogies (Erben et al. 2009) anchored in blended learning and collaborative professional development. Through blended learning, the aim of the project was two-fold: (1) learning English for social interaction purposes and (2) learning English for curriculum purposes (Banfi and Rettaroli 2012). It may be noticed that while the first part of the aim seems to be underpinned by Task-Based Learning (Willis and Willis 2007), the second part may be associated with language-driven Content and Language Integrated Learning (Banegas 2012) as the authors of the course, detailed lesson plans and materials (Banfi and Rettaroli 2012) drew on curricular content to teach English.

Banfi and Rettaroli (2012) developed complete syllabi and detailed lessons plans for each week with instructions in English and Spanish. Each set of Lessons A-B-C started with the following information in a table: level, unit, week, lesson, topic, vocabulary, grammar, phonology, functions, text genres, classroom language, tasks, and a list of digital materials with hyperlinks and printed materials to be used. This table was followed by the three lesson plans in the cycle (Figure 1). Each lesson plan consisted of these stages: warmer, presentation of learning outcomes, presentation of new language items in context, recognition of new language items, practice, focus on pronunciation, tasks for language skills, self-assessment, optional activities, and homework. In addition, the set included the printed flashcards, game boards, and handouts that supported some of the activities found in the lessons. 
This is a peer-reviewed, accepted author manuscript of the following research article: Banegas, D. L. (2013). ELT through videoconferencing in primary schools in Uruguay: first steps. Innovation in Language Learning and Teaching, 7(2), 179188. https://doi.org/10.1080/17501229.2013.794803

In order to support teachers and encourage their use of the XOs, Plan Ceibal developed a learning management system (LMS) called CREA. Conceived as a platform for constructive learning by enabling course management, access, and tracking of progress (Cavus 2011), CREA hosted all lesson plans and materials such as flashcards, videos, audios, songs, online games, and handouts to be accessed by the teachers involved. In addition, CREA offered various fora through which CTs, RTs, e-moderators, and lesson plan writers could share their views on lesson planning and materials and language development before and after lesson delivery. However, CREA was never accessed by the learners, and therefore it was a collaborative environment for course developers, RTs, and CTs.

\section{Teacher development courses}

Compton (2009) remarks that digital technologies in education prompt the need for new teaching approaches and teaching skills as there is a shift in perceptions of time, space, and ways of engaging students, and constructing knowledge. Based on Hampel and Stickler's (2005) skills pyramid for online language teaching, Compton (2009) developed a framework in which a set of technical, pedagogical, and evaluation skills are suggested along a continuum of teacher expertise.

These aspects were considered to develop teachers professionally to ensure project success and involvement. In order to understand the dynamics and rationale behind the project, CTs participated in a four-day in-service orientation course two weeks before launching the project. In this course they had the opportunity to meet the lesson plan and course writers, some remote teachers, and the e-moderators for the language improvement course. They also received input and experiential sessions on communicative language teaching, language development, the use of some online resources, and CREA navigation as they would find there all the necessary materials and sources.

Throughout the pilot phase and beyond, CTs took a self-access language improvement online course and received extra support from e-moderators whose mission was to encourage the teachers and provide extra learning and technical support. CTs were divided into groups of 10 participants and were linked to an e-moderator based in Buenos Aires. Each e-moderator facilitated two Skype meetings a month to help with self-assessment and evaluation of the course and also to discuss concerns or ideas which the CTs wished to share as regards the lesson cycle. One aim of enrolling CTs on an English course is to teach them English even when it means that they will be only a few steps ahead of their own learners. However, the long-term aim is to train them to become future RTs so that ownership and sustainability of the whole project moves to the hands of Uruguayan teachers. 
This is a peer-reviewed, accepted author manuscript of the following research article: Banegas, D. L. (2013). ELT through videoconferencing in primary schools in Uruguay: first steps. Innovation in Language Learning and Teaching, 7(2), 179188. https://doi.org/10.1080/17501229.2013.794803

In relation to RTs, they were offered orientation days and webinars during the development of the pilot phase. These instances did not take place in advance as the RT profiles indicated that they had experience in teaching through blended learning. Through webinars and face-to-face discussions, RTs had the opportunity to discuss lesson plans and the rationale behind lesson planning (Banfi and Rettaroli 2012) with the lesson plan writers. This was prompted by the need to discuss the relationship between Task-Based Learning, teacher development, and technology (Hauck 2010; Raith and Hegelheimer 2010) in this particular context. They also took the opportunity of webinars to exchange experiences and offer feedback. They also received training on the use of digital technologies, file sharing, videoconferencing handling, and CREA navigation. Furthermore, RTs organised themselves in such a way that peer observation emerged during the first weeks of remote lessons.

\section{Lesson cycle}

As shown in Figure 1, the lesson cycle was initiated with planning and evaluation (PaE) session. This was followed by the videoconference-supported lesson led by the RT and two face-2-face lessons in the hands of the CT. Within the framework of collaborative professional development mediated through digital technologies, $\mathrm{PaE}$ was envisaged as a space to be carried out through Skype since one of its main advantages is that it has enabled 'video-enhanced tandem learning' (Godwin-Jones 2007, 3) not only among learners but teachers.

I should point out that both groups of EFL remote teachers and classroom teachers were experienced professionals who shared an understanding of general pedagogy and classroom dynamics. However, the latter lacked subject-matter knowledge and specific didactics and therefore it was necessary that they worked collaboratively in a state which promoted equality, awareness, and informed decisions.

During each PaE meeting through Skype, each remote teacher (RT) and classroom teacher (CT) went over the set of three lessons in order to discuss adaptations of activities and materials and agree on the roles and strategies to be used in each lesson and anticipate certain challenges and how to overcome them. Cycle after cycle, this PaE session also acted as a space for evaluation and reflection which would then be passed on to the lesson plan writers and materials developers for future adaptations and revised versions. In general terms and as the pilot phase evolved, these PE sessions were around 30 minutes as the bond between RT-CT became more solid and there was full understanding of the pedagogical intent behind the overall course. 
This is a peer-reviewed, accepted author manuscript of the following research article: Banegas, D. L. (2013). ELT through videoconferencing in primary schools in Uruguay: first steps. Innovation in Language Learning and Teaching, 7(2), 179188. https://doi.org/10.1080/17501229.2013.794803

Undoubtedly, Lesson A was the most innovative component of the project. Delivery of remote lessons on a large scale via videoconferencing is an exciting and challenging departure in the field of foreign language teaching and learning. This required the installation of videoconferencing equipment and fibre optic cables in Uruguayan classrooms as well as Argentinian and Colombian premises from where RTs would deliver the lessons. Each videoconferencing set included cameras and sound equipment which could be handled remotely, this means that a RT in Buenos Aires could control the camera in a school in Uruguay.

In this lesson, RT were expected to introduce and practise new language content in an interactive manner using the full functionality of the videoconferencing technology and file/desktop sharing from RT's own computer. In this respect, the lesson featured the use of desktop sharing through commercial software and therefore the RT could show PowerPoint presentations, online games, video clips, or digital interactive activities such as puzzles or jigsaws. Lesson A was envisaged as highly interactive but the main focus was on interaction between the RT and the learners with the RT providing a good model. In this sense, Lesson A was the most important lesson in the cycle since it was the only time in which learners could have quality input from a qualified EFL teacher. It should be mentioned that the lesson was carried out in English but also in Spanish so as not to leave the classroom teacher outside. Although initially conceived as a co-led lesson, the CT provided support for the RT, for example by assisting in classroom management, organising learners into groups, and suggesting a change in the lesson pace or activities depending on learners' mood and classroom atmosphere.

On the one hand, RTs were perceived as second generation tutors (Nissen and Tea 2012) as they did not design the course but their feedback was taken into account to produce improved version of lesson plans and materials. However, as Nissen and Tea (2012) recommend, RTs were periodically asked to provide feedback through online surveys and interviews in order to allow them to influence course design. On the other hand, RTs were considered the experts, and they were in a subject-specific sense. However, this did not create any power issues in the RT-CT relationship since, after all, both were teachers with many years of experience. While the RT knew English, the CT knew the context and the learners.

Lessons B and C were delivered by the CT mostly in Spanish though following the lesson plan and using some classroom language in English. These lessons built on the language presented and practised by the RT, using a variety of activities which promoted language skills, classroom organisation patterns, and the XO laptop. Along these lines, CT showed videos, suggested online games, and asked learners to produce their own materials. Based on the professionally developed resources, learners made their own flashcards, games such as dominoes, and digital stories. 
Since CT knew the context and their learners more than their remote counterparts, they were in a better position to introduce changes in the lessons. This resulted in CT developing their own activities based on the ones suggested in the lesson plans and CREA or following their learners' preferences and styles. Some CT who were proficient in the use of digital technologies exploited the benefits of the videoconferencing equipment by employing the 52" screen as a board. These CT used Word and PowerPoint to scaffold sentence patterns, vocabulary, and collaboration. Some teachers went further and developed tests for their own classes but this was discouraged as the tests contained several language mistakes and the procedures did not match the course aims or activities explored.

Similarly to RTs, CTs were also interviewed and their feedback was taken into account for lesson plan and materials development. Feedback was usually concerned with the nature and number of activities per lesson plan and some aspects of materials development such as size of flashcards or target audience of videos.

\section{Opportunities ahead}

This contribution is the first attempt to disseminate this innovative practice. My report is descriptive and does not seek to analyse or evaluate the project even when there are invaluable data obtained through classroom observations, interviews, and surveys. However, there are a number of areas which could be viewed as opportunities.

The innovative nature of this project in the Uruguayan context is invaluable territory for research. Starkey (2011) points out the need for research to make the link between digital technologies and teaching/learning explicit through reliable examination of the extent to which this link is effective. Along these lines, research needs to explore the quality of language learning and its outcomes through blended learning and the collaboration of qualified EFL remote teachers and classroom teachers with little knowledge of English. This latter aspect is also an invitation to explore teacher identities and status underpinned by an emancipatory approach in which teachers' ignorance could be turned into a positive and engaging experience (Rancière 2007) since the teacher's role is not to explain but to engage, inspire, and empower.

Apart from research which could expand on several fronts, there are other vital areas which are intimately related to the conception of the project, its rational, and growth. In relation to ownership, it should be remembered that all the ELT experts involved in the project are not based in Uruguay but elsewhere. Rather than perceiving this fact as a challenge, it may be a good opportunity for Plan Ceibal to delineate actions which aim at longer teacher training 
programmes which prepare Uruguayan teachers to take full control of the teaching, both face-to-face and remote.

I see project ownership inextricably bound to sustainability particularly beyond 2015. Sustainability is dependent upon involving Uruguayan stakeholders in all aspects of the project, not only lesson delivery but also course design and materials development perhaps as envisaged as a joint venture. During the pilot phase and at least the first year of the expansion phase, the project relies on classroom teachers' voluntary work and goodwill. However, CTs have reported that lesson preparation, the language improvement course and $\mathrm{PaE}$ are more time consuming than initially agreed.

\section{Conclusion}

In this brief article I described the pilot phase implementation of an English course for primary school learners in Uruguay through a teaching model which integrates XO laptop computers, videoconferencing led by remote EFL teachers, face-to-face lessons delivered by classroom teachers, and teacher development courses. I explained the project design and how it is inscribed in the intersection between Task-Based Learning and blended learning. I described the lesson cycle and how PaE served as a collaborative space for discussing, adapting, and planning lessons. I finally outlined the opportunities ahead connected to research, ownership, and sustainability.

Plan Ceibal en Inglés is a territory full of opportunities to explore given its scope and largescale implementation. Future publications based on this project will need to look into the dynamics and ecology of implementation and how the project shapes and is shaped by the interrelations among all stakeholders. Most importantly, readers will be interested in reading research reports which examine how digital technologies are successful mediators for foreign language learning in a model where teachers learn English together with their students.

\section{References}

Banegas, D. 2012. Integrating content and language in English language teaching in secondary education: Models, benefits, and challenges. Studies in Second Language Learning and Teaching 2: 111-136.

Banfi, C., and S. Rettaroli. 2012. Manual para Docentes. Versión agosto 2012. Plan Ceibal en Inglés/British Council.

Cavus, N. 2011. Selecting a learning management system (LMS) in developing countries: instructors' evaluation. Interactive Learning Environments

DOI:10.1080/10494820.2011.584321 
This is a peer-reviewed, accepted author manuscript of the following research article: Banegas, D. L. (2013). ELT through videoconferencing in primary schools in Uruguay: first steps. Innovation in Language Learning and Teaching, 7(2), 179188. https://doi.org/10.1080/17501229.2013.794803

Compton, L.K.L. 2009. Preparing language teachers to teach language online: a look at skills, roles, and responsibilities Computer Assisted Language Learning 22: 73-99.

Cyranek, G., ed., 2011. Plan Ceibal in Uruguay. From pedagogical reality to an ICT road map for the future. Montevideo: UNESCO.

Elke Nissen, E., and E. Tea. 2012. Going blended: new challenges for second generation L2 tutors. Computer Assisted Language Learning 25:145-163.

Erben, T., R. Ban, and M. Castañeda. 2009. Teaching English language learners through technology. New York/Abingdon: Routledge.

Godwin-Jones, R. 2012. Digital videos revisited: storytelling, conferencing, remixing. Language Learning \& Technology 16: 1-9.

Hampel, R., and U. Stickler. 2005. New skills for new classrooms: Training tutors to teach languages online. Computer Assisted Language Learning 18: 311-326.

Hauck, M. 2010. The enactment of task design in tellecolaboration 2.0. In Task-based language learning and teaching with technology, ed. M. Thomas and H. Reinders, 197-217. London/New York: Continuum.

Helms, S. A. 2012. Blended/hybrid courses: a review of the literature and recommendations for instructional designers and educators. Interactive Learning Environments DOI: $10.1080 / 10494820.2012 .745420$

Mitra, S., and M. Quiroga. 2012. Children and the internet. A preliminary study in Uruguay. International Journal of Humanities and Social Sciences 15: 123-129.

Raith, T., and V. Hegelheimer. 2010. Teacher development, TBLT, and technology. In Task-based language learning and teaching with technology, ed. M. Thomas and $\mathrm{H}$. Reinders, 154-175. London/New York: Continuum.

Rancière, J. 2007. El maestro ignorante. Cinco lecciones sobre la emancipación intelectual. Buenos Aires: Libros del Zorzal.

Randerson, J. 2008. Risk and experiment: Emerging technology in developing nations. Continuum: Journal of Media \& Cultural Studies 22: 817-825.

Sharma, P., and B. Barrett. 2007. Blended learning. Using technology in and beyond the language classroom. Oxford: Macmillan.

Shen, P., T. Lee, and C. Tsai. 2011. Applying blended learning with web-mediated selfregulated learning to enhance vocational students' computing skills and attention to learn. Interactive Learning Environments 19: 193-209.

Starkey, L.2011. Evaluating learning in the 21st century: a digital age learning matrix. Technology, Pedagogy and Education 20:19-39.

Ushioda, E. 2011a. Why autonomy? Insights from motivation theory and research. Innovation in Language Learning and Teaching 5: 221-232.

Ushioda, E. 2011b. Language learning motivation, self and identity: current theoretical perspectives. Computer Assisted Language Learning 24: 199-210.

Willis, D., and J. Willis. 2007. Doing task-based teaching. Oxford: Oxford University Press. 